\title{
The Business Cycle And Competition In The U.S. Brewing Industry
}

Craig A. Gallet, (Email: cgallet@juno.com), California State University at Sacramento Patricia J. Euzent, (Email: peuzent@bus.ucf.edu), University of Central Florida

\begin{abstract}
:
Recent game-theoretic models of cartel behavior assess the sustainability of cooperation in the presence of demand fluctuations. Depending on the stochastic assumptions of demand, different outcomes are predicted. Accordingly, this paper investigates the effects of demand fluctuations on competition in the U.S. brewing industry. The results show that competition among brewers is greater during periods associated with significant negative shocks to demand, lower observed demand, lower expected future industry profit, and lower advertising.
\end{abstract}

\section{Introduction}

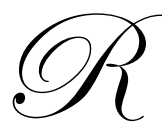

ecent game-theoretic studies of the effect of demand fluctuations on competition focus on cartel stability over the business cycle. For example, Green and Porter (1984) argue that in a market with a stochastic demand it is more difficult to detect cheating, since an observed lower market price could be the result of cheating or an unobserved drop in demand. In such an environment, Green and Porter (GP) suggest that a trigger price mechanism could be used to sustain cooperation. In particular, an observed price below the trigger price is deemed unlikely to occur from a random drop in demand. Inferring that cheating has occurred, a punishment phase ensues. Unfortunately, although this policy is severe enough to deter cheating, in order to maintain credibility of the punishment cooperating firms must price more competitively whenever price drops below the trigger level, even though they know that such a drop is due to a fall in demand. Hence, the GP model contends that firms will behave more competitively during periods with significant unobserved drops in demand. ${ }^{1}$

Rotemberg and Saloner (1986) offer an alternative to the GP model. Namely, assuming that contemporaneous demand is observed but subject to identically and independently distributed (i.i.d.) shocks, Rotemberg and Saloner (RS) argue that a cartel will behave more competitively during periods of high demand. The reasons for this are quite intuitive. First, during periods of observed high demand, since any firm that cheats on the cooperative agreement expects to reap significant sales, the benefits from cheating are very high. Second, given the assumption of i.i.d. demand shocks, firms that cheat during periods of high demand can expect to be punished in the future when demand and profit return to normal levels. ${ }^{2}$ Therefore, the cost to a firm from cheating, in terms of the sacrifice of its share of expected future industry profit, is lower. Knowing that the temptation to cheat is greatest when observed demand is high and expected future industry profit is low, cooperating firms then price more competitively during such periods to deter cheating. ${ }^{3}$

Perhaps driven by the affection held by the consumers of its product, competition in the U.S. brewing industry has attracted the attention of many. According to Elzinga (1995), the brewing industry has become increasingly dominated by a few major brewers. Moreover, since the 1950s changing conditions have led to fluctuations in the demand for beer from year to year. Accordingly, this paper investigates the effect of demand

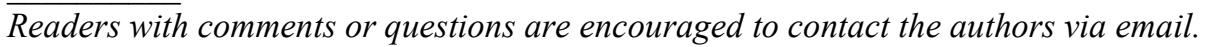

fluctuations on competition in the brewing industry. In Section II, we briefly summarize the characteristics of the brewing industry that support its use as a candidate to evaluate these theories. Section III presents the empirical model, with the data and empirical results provided in Section IV. The paper concludes with a summary in Section 
V. Section VI offers suggestions for future research.

\section{The U.S. Brewing Industry}

Since the theories discussed above pertain to firms operating in a tight oligopoly in the presence of demand fluctuations, several features of the U.S. brewing industry suggest that it may be an ideal candidate to evaluate these theories. First, as indicated in Table 1, concentration in the industry has been increasing over the past 50 years, leading to a market that is currently dominated by a few major brewers.

Table 1. U.S. Brewing Industry Concentration for Selected Years.

\begin{tabular}{cccc}
\hline Year & $\begin{array}{c}\text { 5-Firm } \\
\text { Concentration } \\
\text { Ratio }\end{array}$ & $\begin{array}{c}\text { 10-Firm } \\
\text { Concentration } \\
\text { Ratio }\end{array}$ & $\begin{array}{c}\text { Herfindahl } \\
\text { Index }\end{array}$ \\
1947 & 19.0 & 28.2 & 140 \\
1954 & 24.9 & 38.3 & 240 \\
1958 & 28.5 & 45.2 & 310 \\
1964 & 39.0 & 58.2 & 440 \\
1968 & 47.6 & 63.2 & 690 \\
1974 & 64.0 & 80.8 & 1080 \\
1978 & 74.3 & 92.3 & 1292 \\
1981 & 75.9 & 93.9 & 1614 \\
1984 & 87.3 & 94.2 & 1938 \\
1987 & 87.9 & 93.9 & 2280 \\
1990 & 88.6 & 94.3 & 2565 \\
1992 & 87.6 & 93.4 & 2594 \\
\hline
\end{tabular}

Source: Elzinga (1995).

Second, in light of the extensive advertising requirements to effectively compete in the industry, competition from new entrants is limited. Third, Elzinga (1995), Gallet and List (1998), and the Federal Trade Commission (1978) point out that changes in the demographics of beer consumers (such as the increasing share of younger drinkers following the baby boom years), changes in policy (such as adjustments to the minimum allowable drinking age), and concerns over the health consequences of drinking have contributed to structural changes in the demand for beer over time. Indeed, McGahan (1995) provides evidence that demand fluctuations affected competition among brewers immediately following the repeal of Prohibition in 1933.

\section{The Empirical Model}

We estimate the impact of demand fluctuations on the strength of competition in the brewing industry using a market demand and supply model. To begin, consider the following demand for beer:

$$
\mathrm{Q}_{\mathrm{t}}=\mathrm{f}\left(\mathrm{P}_{\mathrm{t}}, \mathrm{Y}_{\mathrm{t}}, \varepsilon_{\mathrm{t}}\right)
$$

where $Q_{t}$ is the quantity of beer in period $t, P_{t}$ is the price of beer in period $t, Y_{t}$ is a vector of exogenous factors in period $t$ thought to affect the demand for beer, and $\varepsilon \square_{t}$ is a stochastic (error) term in period $t$.

Similar to Appelbaum (1982), Bresnahan (1982), and many others, quantity is determined via a supply relationship, given by:

$$
\mathrm{P}_{\mathrm{t}}=\mathrm{MC}_{\mathrm{t}}-\lambda_{\mathrm{t}} \cdot \mathrm{P}_{\mathrm{t}} \cdot \mathrm{Q}_{\mathrm{t}}+\mathrm{v}_{\mathrm{t}}
$$


where $\mathrm{MC}_{\mathrm{t}}$ is marginal cost in period $\mathrm{t}, \mathrm{P}_{\mathrm{t}}{ }^{\prime}$ is the slope of the inverse demand in period $\mathrm{t}, \mathrm{v}_{\mathrm{t}}$ is an error term in period $t$, and $\lambda_{t}$ is a gauge of the degree of competition in period $t$. For example, $\lambda_{t}$ equal to 0 coincides with a competitive market, whereas $\lambda_{t}$ equal to 1 coincides with joint profit maximization. Lower (higher) values of $\lambda_{t}$ within the zeroone interval indicate less (more) departure of price from marginal cost, and hence a higher (lower) degree of competition.

Similar to recent studies (see, for example, Rubinovitz (1993) and Barros (1996)) that estimate the competitive effect of different factors by treating $\lambda_{t}$ as a function of these factors, we assume $\lambda_{t}$ depends upon variables relevant to the theories of collusion over the business cycle. In doing so, several issues pertaining to the specification of our model must be addressed. First, since the theories deal with shifts of the demand curve, we adopt a linear specification of demand and use the horizontal intercept $\left(P_{t}=0\right)$ as a measure of the level of demand. ${ }^{4}$

Second, since the GP model focuses on stochastic shifts of demand, whereas the RS model focuses on nonstochastic shifts of demand, we must account for the observed and unobserved levels of demand. Following Baker (1989), we do this by treating the error term $(\varepsilon)$ in the demand equation as the unobserved level of demand and the remaining portion of demand (holding $P_{t}=0$ ) as the observed level of demand. Furthermore, since the GP model predicts that only significant unobserved decreases in demand will trigger more competitive behavior, we need to focus on the negative values of $\varepsilon_{\mathrm{t}}$ when addressing the GP model. McGahan's study of the 1930s brewing industry does this by assuming that $\lambda_{t}$ is a function of a dummy variable (which equals one whenever $\varepsilon \square_{t}<0$ and zero otherwise). However, even though the estimated negative relationship between this dummy variable and $\lambda_{t}$ implies that unobserved decreases in demand coincide with more competitive behavior in the brewing industry, McGahan's approach misses an important point of the GP model, namely that only large unobserved decreases in demand should trigger more competitive behavior. Therefore, to account for this, we use a two-step procedure outlined by Baker (1989). First, after estimating the demand for beer, the residuals from the estimated demand equation become estimates of the demand errors, which are then used to construct the following dummy variable:

$$
\begin{aligned}
\mathrm{D}_{\mathrm{t}} & =1 \text { if } \mathrm{e}_{\mathrm{t}}<-\mathrm{T} \bullet \mathrm{s} \\
& =0 \text { if } \mathrm{e}_{\mathrm{t}} \geq-\mathrm{T} \bullet \mathrm{s}
\end{aligned}
$$

where $e_{t}$ is the demand residual in period $t, s$ is the standard error of the estimate of the demand equation (which is used to account for volatility of the demand curve), and T is a positive scalar. Second, the reported value of T, along with the estimated coefficients of the supply relationship, are determined using a grid search technique. ${ }^{5}$ Consequently, we account for unusual shocks to demand by letting $D_{t}$ take on a value of one only in the presence of truly meaningful unobserved demand reductions.

Third, to account for the predictions of the RS model, we need measures of the level of observed demand $\left(\mathrm{OBS}_{\mathrm{t}}\right)$ and the value of expected future industry profit $\left(\mathrm{E}_{\mathrm{t}}\right)$. Accordingly, since the demand error captures the unobserved level of demand, we use the fitted value of $Q_{t}$, net of the residual (holding $P_{t}=0$ ), as the measure of observed demand. We then follow a procedure outlined by Rotemberg and Woodford (1991) and Gallet and Schroeter (1995) to derive the present discounted value of expected future industry profit as an indicator of expected future industry profit. In particular, current and lagged values of industry profit components (i.e., revenue and cost terms) are used to estimate $\mathrm{E}_{\mathrm{t}}$ following a vector autoregression procedure. However, since this technique comes from existing literature, readers are encouraged to see Rotemberg and Woodford and Gallet and Schroeter for thorough discussions of this technique.

Finally, since advertising has played a role in the behavior of firms in this industry, we adopt the customary approach (see, for example, Comanor and Wilson (1967), Eckard (1987), and Das, Chappell, and Shughart (1993)) of using the advertising-to-sales ratio $\left(\mathrm{AS}_{\mathrm{t}}\right)$ as a means of accounting for the effect of advertising on competition. ${ }^{6}$ To account for the various factors thought to affect competition in the brewing industry, we then assume the following relationship for $\lambda_{t}$ :

$$
\lambda_{\mathrm{t}}=\lambda_{0}+\lambda_{1} \mathrm{D}_{\mathrm{t}}+\lambda_{2} \mathrm{OBS}_{\mathrm{t}}+\lambda_{3} \mathrm{E}_{\mathrm{t}}+\lambda_{4} \mathrm{AS}_{\mathrm{t}}
$$


where the $\lambda_{i}$ 's are estimable parameters and the variables are as previously defined.

The signs of the estimated $\lambda_{\mathrm{i}}$ 's from equation (4) determine the effect of each respective variable on the degree of competition. For example, concerning the role of demand fluctuations, if the GP model is correct, then competition will be greater when demand encounters large negative shocks $\left(\lambda_{1}<0\right)$. Alternatively, if the RS model holds, then competition will be greater when observed demand is high and industry profit is expected to be low in the future $\left(\lambda_{2}<0\right.$ and $\left.\lambda_{3}>0\right)$. Finally, whether advertising plays a pro-competitive or anti-competitive role in the brewing industry will be accounted for by the estimate of $\lambda_{4}$.

To complete the model, we adopt a generalized Leontief cost function, such that when combined with a linear demand, $\lambda_{t}$ is identified. Accordingly, the demand and total cost functions are given by:

and

$$
\mathrm{Q}_{\mathrm{t}}=\alpha_{0}+\alpha_{1} \mathrm{Y}_{1 \mathrm{t}}+\alpha_{2} \mathrm{Y}_{2 \mathrm{t}}+\alpha_{3} \mathrm{Y}_{3 \mathrm{t}}+\alpha_{4} \mathrm{P}_{\mathrm{t}}+\varepsilon_{\mathrm{t}}
$$

$$
\mathrm{TC}_{\mathrm{t}}=\Sigma_{\mathrm{i}} \Sigma_{\mathrm{j}} \beta_{\mathrm{ij}}\left(\mathrm{W}_{\mathrm{it}} \cdot \mathrm{W}_{\mathrm{jt}}\right)^{1 / 2} \mathrm{Q}_{\mathrm{t}}+\Sigma_{\mathrm{i}} \beta_{\mathrm{i}} \mathrm{W}_{\mathrm{it}} \quad(\mathrm{i}, \mathrm{j}=1,2,3)
$$

where, for simplicity, the exogenous factors in total cost and demand $\left(\mathrm{W}_{\mathrm{it}}\right.$ and $\mathrm{Y}_{\mathrm{it}}$ ) have been truncated to include three variables. Solving for marginal cost in equation (6), and substituting equation (4) into the supply relationship, equation (2) becomes:

$$
\begin{aligned}
\mathrm{P}_{\mathrm{t}}= & \beta_{11} \mathrm{~W}_{1 \mathrm{t}}+\beta_{22} \mathrm{~W}_{2 \mathrm{t}}+\beta_{33} \mathrm{~W}_{3 \mathrm{t}}+2 \beta_{12}\left(\mathrm{~W}_{1 \mathrm{t}} \bullet \mathrm{W}_{2 \mathrm{t}}\right)^{1 / 2}+2 \beta_{13}\left(\mathrm{~W}_{1 \mathrm{t}} \bullet \mathrm{W}_{3 \mathrm{t}}\right)^{1 / 2}+2 \beta_{23}\left(\mathrm{~W}_{2 \mathrm{t}} \bullet \mathrm{W}_{3 \mathrm{t}}\right)^{1 / 2} \\
& -\left\{\left(\lambda_{0}+\lambda_{1} \mathrm{D}_{\mathrm{t}}+\lambda_{2} \mathrm{OBS}_{\mathrm{t}}+\lambda_{3} \mathrm{E}_{\mathrm{t}}+\lambda_{4} \mathrm{AS}_{\mathrm{t}}\right) / \alpha_{4}\right\} \bullet \mathrm{Q}_{\mathrm{t}}+\mathrm{v}_{\mathrm{t}}
\end{aligned}
$$

The model, given by equations (5) and (7), is estimated using two steps. First, equation (5) is estimated using two stage least squares (2SLS). Second, using the demand results to construct $\mathrm{D}_{\mathrm{t}}$ and $\mathrm{OBS}_{\mathrm{t}}$, equation (7) is estimated across all possible values of $\mathrm{T}$, the scalar used in $\mathrm{D}_{\mathrm{t}}$. The estimated coefficients of the supply relationship then coincide with the value of $\mathrm{T}$ that minimizes the 2SLS objective function. The data and empirical results are provided in the next section.

\section{Data and Empirical Results}

Data

The model is estimated using annual data over the 1964-1992 period. With respect to demand, total consumption of beer in the U.S. $\left(\mathrm{QB}_{\mathrm{t}}\right)$ is assumed to depend upon U.S. disposable income $\left(\mathrm{INC}_{\mathrm{t}}\right)$, the U.S. population 18 years and older $\left(\mathrm{POP} 18_{t}\right)$, the price of wine $\left(\mathrm{PW}_{\mathrm{t}}\right)$, total advertising expenditures of the brewing industry $\left(\mathrm{AD}_{\mathrm{t}}\right)$, and the price of beer $\left(\mathrm{PB}_{\mathrm{t}}\right)$. Beer consumption, sales expenditure (used to construct the advertising-to-sales ratio), and advertising expenditure data were collected from Brewer's Almanac. Beer and wine prices came from the Handbook of Labor Statistics and the CPI Detailed Report. Figures for the U.S. population 18 years and older and U.S. disposable income were obtained from Current Population Reports and the Economic Report of the President, respectively. Finally, beer and wine prices, disposable income, and advertising expenditures were deflated by the consumer price index, which was also taken from the Economic Report of the President.

As for supply, the average hourly wage of a beer worker $\left(\mathrm{WG}_{\mathrm{t}}\right)$ and the prices of corn $\left(\mathrm{PC}_{\mathrm{t}}\right)$ and barley $\left(\mathrm{PBA}_{\mathrm{t}}\right)$ are included as exogenous shifters of marginal cost. The wage data came from Brewer's Almanac, while the prices of corn and barley were collected from the Survey of Current Business. All prices in the supply equation were deflated by the producer price index, which was obtained from the Economic Report of the President. Given these data, the specifications of demand and supply become:

and

$$
\mathrm{Q}_{\mathrm{t}}=\alpha_{0}+\alpha_{1} \mathrm{INC}_{\mathrm{t}}+\alpha_{2} \mathrm{POP} 18_{\mathrm{t}}+\alpha_{3} \mathrm{PW}_{\mathrm{t}}+\alpha_{4} \mathrm{AD}_{\mathrm{t}}+\alpha_{5} \mathrm{~PB}_{\mathrm{t}}+\varepsilon_{\mathrm{t}}
$$

$$
\mathrm{PB}_{\mathrm{t}}=\beta_{11} \mathrm{WG}_{\mathrm{t}}+\beta_{22} \mathrm{PBA}_{\mathrm{t}}+\beta_{33} \mathrm{PC}_{\mathrm{t}}+2 \beta_{12}\left(\mathrm{WG}_{\mathrm{t}} \cdot \mathrm{PBA}_{\mathrm{t}}\right)^{1 / 2}+2 \beta_{13}\left(\mathrm{WG}_{\mathrm{t}} \cdot \mathrm{PC}_{\mathrm{t}}\right)^{1 / 2}+2 \beta_{23}\left(\mathrm{PBA}_{\mathrm{t}} \cdot \mathrm{PC}_{\mathrm{t}}\right)^{1 / 2}
$$




$$
-\left\{\left(\lambda_{0}+\lambda_{1} \mathrm{D}_{\mathrm{t}}+\lambda_{2} \mathrm{OBS}_{\mathrm{t}}+\lambda_{3} \mathrm{E} \Pi+\lambda_{4} \mathrm{AS}_{\mathrm{t}}\right) / \alpha_{5}\right\} \cdot \mathrm{QB}_{\mathrm{t}}+\mathrm{v}_{\mathrm{t}}
$$

\section{Empirical Results}

The empirical results from the estimation of equations (8) and (9) are reported in Table 2. Since the Durbin-Watson statistic failed to conclusively suggest autocorrelated error terms, equations (8) and (9) were not adjusted for serial correlation. ${ }^{7}$ With respect to the estimated demand equation, as expected we find that demand slopes downward and increases with the U.S. population and the price of wine. Also, the estimated negative coefficient of income suggests that beer is an inferior good. ${ }^{8}$ Finally, advertising has no significant effect on the demand for beer.

Holding the price of beer equal to zero, the results from the estimation of demand are used to construct the observed and unobserved levels of demand. Equation (9) is then estimated across all conceivable values of T, and therefore all possible constructions of $\mathrm{D}_{t}$, where the results are provided in Table 2. With respect to marginal cost, the estimated coefficients offer mixed results. In particular, when evaluated at the sample means, although marginal cost is increasing in the input prices, the negative estimates of several of the marginal cost coefficients fail to support concavity of the cost function. Nonetheless, several interesting results emerge from the estimation of $\lambda_{t}$. First, in support of the GP model, the negative estimate of $\lambda_{1}$ indicates that competition among brewers since the 1960s has been greater during periods associated with significant unobserved decreases in demand. Second, although the positive estimate of $\lambda_{2}$ fails to support the RS claim that greater competition coincides with higher observed demand, the positive estimate of $\lambda_{3}$ does support RS to the extent that greater competition coincides with lower expected future industry profit. Finally, the positive estimate of $\lambda_{4}$ shows that advertising decreases competition in the brewing industry.

\section{Conclusion}

Recent theories of oligopoly behavior provide testable hypotheses concerning the effect of demand fluctuations on competition. In this paper, we estimated an empirical model of the U.S. brewing industry, where the results support several aspects of these theories. Namely, competition in the brewing industry since the 1960s has been greater when demand and expected future industry profit are low. Moreover, we find that advertising promotes market power, and thereby reduces competition among brewers.

\section{Suggestions for Future Research}

While studies of the demand for beer are common in the literature, less attention has been devoted to the supply side of the market. Hence, as an avenue of future research, it is worthwhile to consider alternative models of producer behavior in the brewing industry. For example, since various public policies have been directed towards the industry (ranging from taxes to health warnings), addressing the impact of these policies on the nature of competition in the industry would be of interest.

Table 2. Estimation Results.

\begin{tabular}{lrc}
\hline Parameter & Estimate & t-ratio \\
\hline Demand Parameters: & & \\
\hline$\alpha \square 0$ & 75434000.00 & 0.972 \\
$\alpha \square_{1}$ & $-62892.90^{\mathrm{a}}$ & -3.696 \\
$\alpha{ }_{2}$ & $2537070.00^{\mathrm{a}}$ & 4.779 \\
$\alpha{ }_{3}$ & $782131.00^{\mathrm{b}}$ & 2.776 \\
$\alpha 4$ & 6.70 & 0.918 \\
$\alpha \square 5$ & $-2193770.00^{\mathrm{a}}$ & -8.441
\end{tabular}




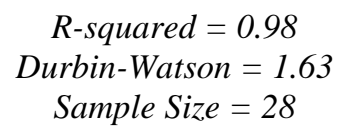

Supply Parameters:
$\beta \beta_{11}$
$\beta_{22}$
$\beta_{33}$
$\beta_{12}$
$\beta_{13}$
$\beta_{23}$
$\lambda_{0}$
$\lambda_{1}$
$\lambda_{2}$
$\lambda_{3}$
$\lambda_{4}$

$\begin{array}{cc}-5.97^{\mathrm{b}} & -2.235 \\ -437.78^{\mathrm{b}} & -2.149 \\ -329.00^{\mathrm{b}} & -2.030 \\ 34.85^{\mathrm{b}} & 2.334 \\ -7.35 & -0.600 \\ 358.11^{\mathrm{b}} & 2.025 \\ 0.04 & 1.008 \\ -0.38 \mathrm{E}-02^{\mathrm{a}} & 4.310 \\ 0.65 \mathrm{E}-09^{\mathrm{a}} & 8.109 \\ 0.32 \mathrm{E}-12^{\mathrm{a}} & 5.691 \\ 0.14^{\mathrm{a}} & 5.410\end{array}$

$$
\begin{gathered}
R \text {-squared }=0.81 \\
\text { Durbin-Watson }=2.14 \\
\text { Sample Size }=28 \\
T=1.24
\end{gathered}
$$

\footnotetext{
${ }^{a}$ Significant at $1 \%$ level.

${ }^{\mathrm{b}}$ Significant at $5 \%$ level.
}

\section{Notes}

1 Empirical support for the GP model is provided by Porter's (1983) and Ellison's (1994) studies of the 1880 s railroad industry and Baker's (1989) study of the steel industry.

2 Rotemberg and Saloner's assumption of i.i.d. demand shifts implies that expected future demand is independent of current demand. Haltiwanger and Harrington (1991) and Bagwell and Staiger (1997) extend the RS model by allowing demand shifts to be correlated over time.

3 Empirical support for this model is provided by Gallet and Schroeter's (1995) study of the rayon industry and Rosenbaum and Sukharomana's (2001) study of the cement industry.

$4 \quad$ Often cited as support for the GP model, several studies (e.g., Domowitz, Hubbard, and Petersen (1986)) have regressed price-cost margins on industry sales and found that competition is greater (i.e., price-cost margins are lower) when sales are lower. However, since the game-theoretic models are based upon shifts of demand, one limitation of these studies is that using sales as a regressor makes it difficult to determine if such observations are the result of shifts or movements along the demand curve. Our approach specifically addresses shifts of demand.

5 Specifically, the coefficients of the supply relationship are estimated across all conceivable values of T, where the reported results correspond to that iteration which optimizes the objective function used to estimate supply.

6 There are different viewpoints concerning the effect of advertising on competition. For example, incumbent firm advertising may raise entry barriers by forcing entrants to aggressively advertise to secure market share, thereby decreasing competition. Alternatively, advertising can provide information to consumers regarding price, quality, and location, thereby stimulating entry and competition.

7 When both equations were adjusted for serial correlation, the autocorrelation coefficients were insignificantly different from zero. Hence, we only report results for the unadjusted equations.

8 Niskanen (1962), Comanor and Wilson (1974), and Gallet and List (1998) also find beer to be an inferior good. 


\section{References}

1. Appelbaum, E., "The Estimation of the Degree of Oligopoly Power," Journal of Econometrics, Vol. 19, pp. 287-299, 1982.

2. Bagwell, K. and Staiger, R., "Collusion over the Business Cycle," Rand Journal of Economics, Vol. 28, pp. 82-106, 1997.

3. $\quad$ Baker, J., "Identifying Cartel Policing under Uncertainty: The U.S. Steel Industry, 1933-1939," Journal of Law and Economics, Vol. 23, pp. 47-76, 1989.

4. Barros, P., "Competition Effects of Price Liberalization in Insurance," Journal of Industrial Economics, Vol. 46, pp. 267-287, 1996.

5. Beer Institute, Brewer's Almanac. Washington, D.C., 1995.

6. Bresnahan, T., "The Oligopoly Solution Concept is Identified," Economics Letters, Vol. 10, pp. 87-92, 1982.

7. Comanor, W. and Wilson, T., "Advertising, Market Structure, and Performance," Review of Economics and Statistics, Vol. 49, pp. 423-440, 1967.

8. _ _ Advertising and Market Power, Harvard University Press. Cambridge, MA, 1974.

9. Council of Economic Advisors, Economic Report of the President, Washington, D.C., 1995.

10. Das, B., Chappell, W. and Shughart, W., "Advertising, Competition, and Market Share Instability," Applied Economics, Vol. 25, pp. 1409-1412, 1993.

11. Domowitz, I., Hubbard, G., and Petersen, B., "Business Cycles and the Relationship between Concentration and Price-Cost Margins," Rand Journal of Economics, Vol. 17, pp. 1-17, 1986.

12. Eckard, E., "Advertising, Competition, and Market Share Instability," Journal of Business, Vol. 60, pp. 539-552, 1987.

13. Ellison, G., "Theories of Cartel Stability and the Joint Executive Committee," Rand Journal of Economics, Vol. 25, pp. 37-57, 1994.

14. Elzinga, K., "The beer industry," in The Structure of American Industry (W. Adams and J. Brock, eds.), Prentice Hall Publishing Company, Englewood Cliffs, NJ, 1995.

15. Federal Trade Commission, The brewing industry, Washington, D.C., 1978.

16. Gallet, C. and Schroeter, J., "The Effects of the Business Cycle on Oligopoly Coordination: Evidence from the U.S. Rayon Industry," Review of Industrial Organization, Vol. 10, pp. 181-196, 1995.

17. Gallet, C. and List, J., "Elasticities of Beer Demand Revisited," Economics Letters, Vol. 61, pp. 67-71, 1998.

18. Green, E. and Porter, R., "Noncooperative Collusion under Imperfect Price Information," Econometrica, Vol. 52, pp. 87-100, 1984.

19. Haltiwanger, J. and Harrington, J., "The Impact of Cyclical Demand Movements on Collusive Behavior," Rand Journal of Economics, Vol. 22, pp. 89-106, 1991.

20. McGahan, A., "Cooperation in Prices and Capacities: Trade Associations in Brewing after Repeal, Journal of Law and Economics, Vol. 38, pp. 521-557, 1995.

21. Niskanen, W., "The Demand for Alcoholic Beverages," Unpublished Ph.D. Dissertation. University of Chicago, 1962.

22. Porter, R., "A Study of Cartel Stability: The Joint Executive Committee, 1880-1886," Bell Journal of Economics, Vol. 14, pp. 301-314, 1983.

23. Rosenbaum, D. and Sukharomana, "Oligopolistic Pricing over the Deterministic Market Demand Cycle: Some Evidence from the U.S. Portland Cement Industry," International Journal of Industrial Organization, Vol. 19, pp. 863-884, 2001.

24. Rotemberg, J. and Saloner, G., "A Supergame-Theoretic Model of Price Wars during Booms," American Economic Review, Vol. 76, pp. 390-407, 1986.

25. Rotemberg, J. and Woodford, M., "Markups and the Business Cycle," NBER Macroeconomics Annual, pp. 63-129, 1991.

26. Rubinovitz, R., "Market Power and Price Increases for Basic Cable Services since Deregulation," Rand Journal of Economics, Vol. 24, pp. 1-18, 1993.

27. U.S. Department of Commerce, Bureau of the Census, Current Population Reports, Washington, D.C., Various Years. 
28. _ _ Survey of Current Business, Washington, D.C., Various Years.

29. U.S. Department of Labor, Handbook of Labor Statistics, Washington, D.C., Various Years.

30. _ CPI Detailed Report, Washington, D.C., Various Years.

Notes 